\title{
More “Nudging” for pro-environmental behavior
}

\author{
Malte Albrecht \\ Fresenius University for Applied Sciences, Skip-Institut e.V.
}

\begin{abstract}
The effects of global warming became aware for everyone during the last years. Most of the scientists support the opinion that the partly rough changes in the climate and the pollution of the planet are closely related to the behavior of the peoples around the world. One could follow the track of Yvan Bourgon and support the idea to clean up the oceans with the help of boats (The sea cleaners"-project). Or one could stand behind the idea of Topher White to hang smartphones in endangered rainforesttrees to check if illegal deforestation is taking place (The rainforest connection). These attempts seem to be honorable and worthy to support, but it seems to be quiet symptom-oriented and not eradicating the real problem. One promising way that could have a formative influence on the behavior is not coming from a technical field but from Psychology. The human behavior itself is a meaningful research-topic in Psychology and so it is worthy to have a glance on the ideas that researchers have to influence the human behavior.
\end{abstract}

Keywords:

Pro-environmental Behavior, Nudging,

\section{Introduction}

Libertarian Paternalism or positive advice?

Gigerenzer (2015) defines the main aspects of libertarian paternalism, which functions in the following way: A policy maker (in his writings a "benevolent choice architect) determines what is best for everyone. The people instead, however, are rarely asked, assuming that they lack rationality. 
This is the objective. Then comes the engineering: A nudge is introduced in order to change people's behavior into the desired direction, without incentives, coercion or education. Libertarian paternalists justify the need of the governments to nudge their citizens rather than educate them in the first place by calling upon psychological research that has allegedly shown people's lack of rationality and inability to correct their errors.

Each person needs to make huge numbers of decisions day by day, consciously and unconsciously. A part of those decisions are not simple to make, mainly because of the challenge that we are not in the possession of every detail and the corresponding impact of each decision. For example: An expert in the knowledge to cure tooth pain is the dentist. If he/she would present only one way of filling your tooth of what he or she is convinced of, then it would be paternalism and surely one would feel uneasy with that only solution. To avoid this scenario, dentists are obliged to tell you at least more than one possible treatment. From this point of view, the patient can accept the professional opinion of the doctor but also has the freedom of choice. So the dentist becomes a decision architect who influences the patient. Another convincing example is that of Thaler, Sunstein \& Balz (2010): As the director of food services in a large city school system runs a series of experiments which alters the way in which the food is displayed in the cafeterias, he/she most likely will recognize that foods in the beginning or the end of the line are more likely to be eaten. Also foods on eye level are more likely to be consumed than those which are displayed more above or below of sight. With this newfound knowledge, the director has new options available that are worthwhile to consider:

1. Choose the food order randomly.

2. Arrange the food to make the students best off, consider everything.

3. Hope to arrange the food in a way that the kids would choose to do.

4. Maximize sales of the items from the suppliers that are willing to offer the largest bribes.

5. Maximize all profits, period.

Option 1, arranging the food randomly, could be considered fair-minded or in a more simple sense, neutral. But then the purpose of a practical food service director would become meaningless. Option 2 has a good appeal as few would argue that the kids would be better off eating more fruits and vegetable, less meat, sweets and fries. This option could be considered paternalistic, but the alternatives aren't better.

To avoid intrusion, option 3 seems to be an honorable attempt. Try to adapt what the children might like for themselves. Maybe the director should follow people's wishes. But as we have seen before this option is difficult to be objectively neutral as even the order in which the food is displayed influences the choosing which the students would consider as their own. Option 4 might appeal to a corrupt cafeteria manager, manipulating the order of the food to exploit power. But if the director is an honorable and honest person, this would not come into play.

(was ist mit Option 5?)

According to Hansen any attempt to influence people's judgment, choice or behaviour in a predictable way, possible because of cognitive biases in individual and social decision-making posing barriers for people to perform in their own interest rationally and working by making use of those biases as an integral part of such attempts, is a nudge.

So it means that a decision-architect influences the behavior of people in a predictable way without excluding options, without changing economic incentives in drastic ways and it needs to be easy to bypass this. A typical example was mentioned above - that some companies present fruits at eye level at the canteen. No nudging would be, banning junk food from the canteen at all. Therefore, co-workers are reminded of consuming fruits, before getting their food. In this case, they used priming to provoke the nudging. According to Hansen any attempt to influence people's judgment, 
choice or behaviour in a predictable way, possible because of cognitive biases in individual and social decision-making posing barriers for people to perform in their own interest rationally and working by making use of those biases as an integral part of such attempts, is a nudge.

\section{System 1 \& System 2 and Nudging}

One can connect the concept of nudging with Kahnemans System-theory: This theory distinguishes between two systems. System 1 distinguishes from System 2 by being fast, automatic and intuitive while System 2 happens slow, deliberate and in a conscious way. This would mean that System 1 guides us through large parts of our daily decisions and routines, like taking a shower or riding a bike while System 2 relies on much more mental effort e.g. make important choices about the further course of life. Therefore System 1 relies on heuristics, biases and mental shortcuts, while System 2 consists of detailed multi criteria evaluations (Lehner, Mont \& Heiskanen, 2016).

Thaler and Sunstein (2008) point out, that nudging can interact with System 1 and is able to correct decisions: If the intuitive way of making decisions is interrupted by a nudge, it makes people overthink their prior "fast" decision. So there is a chance to lead the attention in a different direction. Additionally it is possible to shape automatic and intuitive behavior right from the beginning.

There are some situations, where it might be meaningful to use nudging e.g.: Profit is now available and the side-effects occurs later (e.g. smoking cigarettes) and difficult decisions that are not made every day (Thaler, Sunstein \& Balz, 2010). Another example would be the question of organ donations: There is a vivid political discussion in Germany in which way the organ donation could be enhanced in its quantity. Here we see that politicians do not want to be seen as "guiding fathers" who know what is best for the people. Several possibilities got reflected in the public but did not end up in a political suggestion and solution. But there are convincing and working examples from other countries, which could be adopted or copied in a fitting way to Germany as in the case discussed by Johnson et al. In this approach some countries have adopted an opt-out approach to organ donation called "presumed consent". Clearly, the number of people who agree to make their organs available drastically increases, however, some people strenuously object to this policy. Their thinking is that the government should not presume anything about their organs. A compromise would be mandated choice. In Illinois, when drivers go to get their license renewed, including a new photo, there is a mandatory question "do you wish to be an organ donor?". After this question, they can pick up their license. This procedure has produced a 60 percent sign up rate compared to the national average of 38,4 percent. Since the choice is explicit rather than implicit, family members of deceased donors are less likely to object.

The question is in which possible ways those behaviors can be encountered - priming was mentioned as one possible solution. Thaler, Sunstein \& Balz (2010) suggest several ways to meet these behaviors: Like "temptation", "mental accounting", "social influence", "group pressure" and "framing". One other example is "mapping", it means that you describe the outcome of a decision in an understandable relation. That can be in terms of product choice, like explaining the amount of mega-pixels in the possible size of the printed photo. Alternatively, it might be in environmental terms. Here I like to refer to Cuthbert et al. (2018) - who pointed out that the groundwater level will dramatically decrease as a long-time side effect of the global warming. That is an abstract and longterm effect, but if one wants to reach the people and want to convince them to spare water one could use the "mapping"-tool: The mentioned groundwater problematic can be connected with a comparison in shopping behavior, e.g. that the production of one jeans needs 8000 liter of water. In this way, one does not push people into a certain way, but they get information and gain knowledge about a specific environmental problem. There is another option how "mapping" can be used: where people have a problem in mapping products into money. Thaler Sunstein and Balz (2010) see this as a good example 
for explaining the positive side of mapping by explaining it in terms of using a credit card. It is easy to determine the cost of a candy bar, payed with money. If a candy bar costs 1 euro, then you can calculate the cost of it for 7 days a week. But the simple use of a credit card involves much more calculation: The annual fees for using the card, an interest rate for borrowing money, a fee for making payments late, the interest on purchases made during the month that is normally not charged if your balance is paid off but begins if you make your payment one day late; a charge for buying things in another currency, the indirect fee of higher prices that retailers pass along to consumers to offset the percentage of each transaction the credit card companies take.

Another example of nudging is described by Lehner, Mont \& Heiskanen (2016) - they describe the use of changed default mode as one influential way: Nudging can be used more often where people take the path of least resistance and this is typically the case in everyday life. Lehner, Mont \& Heiskanen (2016) describe how the use of changed default mode can lead to less consumption of resources. In Sweden, as in many other countries, printers are by default configured to print singlesided only. The study, which was evaluated there, showed that $30 \%$ of the paper consumption is determined by this default. Simply by switching the default configuration to double-sided printing paper consumption could be reduced by 15\% (Egebark \& Ekström, 2013). Where consent is presumed, participation is significantly higher than in countries where a person must actively choose to opt into enrolling. The reduction of consumption of resources is an effective way where nudging can lead to pro-environmental behaviour, a crucial point nowadays. Informative billing, metering and displays have been popular energy policy instruments. This feedback on energy consumption, not only informative billing but also smart meters, make the information more actionable. To help to design an easy way of reading electricity consumption is the key for the effectiveness to get savings ranging from 1 to $20 \%$. Fischer (2008) concluded that this feedback is most effective when it's done frequently and involves interaction and choice. This applies to households. Delmas et al. (2013) found that feedback rendered average savings of about 7\%. When the scaling is larger, Darby (2012) pointed out, that wider interventions and rollouts involving much more households on lower savings of about $2 \%$.

Gigerenzer (2015) as one of the influential psychologist on the field of decision-making has a critical view on nudging. He is in worry that nudging is turning into strong libertarian paternalism, which is limited to a hand-full of decision-architects, "who know what is best". This is a reasonable doubt. In his point of view, education is the only way of nudging people in a responsible way. He underlines which aspects would be needed to be a convincing decision-architect. Gigerenzer sees an uttermost importance in following three conditions, firstly, that they do not practice defensive decision making, secondly, that they understand scientific evidence and thirdly, that they have no conflicting interests. In the before mentioned case of the dentist, or generally in health care, libertarian paternalists have pointed out that nudging people would lead to a greater benefit for everyone, but for Gigerenzer this is only true if those three conditions are met. In reality, in the U.S., in Germany and other western countries, these conditions are however not met (Gigerenzer \& Muir Gray 2011). Instead, many health care providers practice defensive medicine. Typically they suggest a second best option, instead of what they believe is best for the patient, to protect themselves from potential lawsuits. A shocking 93\% of 824 doctors in Pennsylvania admitted that they were practicing defensive medicine. This includes unnecessary CT scans, antibiotics and invasive surgery (Studdert et al. 2005). The second condition, understanding scientific evidence, is also often not met. Health statistics are often misinterpreted, $70-80 \%$ of U.S. primary care physicians did not understand survival rate in cancer screening and could easily manipulated into recommending screening, even if its harms exceeded its benefits, according to Wegwarth, Schwartz, Woloshin, Gaissmaier and Gigerenzer in 2012. 
There are already behavioral sciences teams in a big number of countries, which implement nudges (Australia, Germany, Canada, Ireland etc.) (OECD, 2017). We will come back to that point later in the article, when we attached value to two recently published papers concerning nudging: Byerly et al. (2018) conducted a review of 72 studies, including 160 interventions across six domains (family planning, land management, meat consumption, transportation choice, waste production, water use) concerning nudging. They could find clear evidence that nudging can help to implement pro-environmental behavior. The most meaningful interventions in the different fields are as following: Concerning family planning, it is most effective to inform women without their husbands about contraception and give vouchers to them. In land management, there were only a few studies, but they point into the direction that one effective way is to pay forest-owning households money not to cut their trees. Other educational ways did not meet a wide response. Meat consumption alters by changing the menu offerings and reducing the plate sizes. By highlighting environmental issues, the transportation choices turn into a pro-environmental direction. To ask for commitments and implementing norms is a convincing way to change waste production and to enhance water use. All in all Byerly et al. (2018) conclude that contextual interventions seem to be more effective in most parts than educational attempts. Sunstein et al. (2018) wrote the second recently published paper, which I want to reflect on. They concentrated on several countries and could divide them into three different groups: The "principled pro-nudge nations" (like Germany and US), the "nudge enthusiasts" (like South Korea and China) and "cautiously pro-nudge nations" (Denmark and Japan e.g.) (Sunstein et al., 2018). In the article, they point out, that the use of nudging depends on several factors. One main factor is the trust in the public institutions and the government. They point out that there is a general preference for educational nudges. Additionally they could show that it makes a difference, if one introduces the nudges in a transparent or an opaque way. Further, people doubt nudges significantly more, if they are higher educated and live in cities. The use of nudges is not a new phenomenon for politicians in many countries and they are aware of possible advantages (Ruggeri, 2018). In addition, some reforms were implemented which were inspired by nudges (Whitehead et al., 2017). However, many politicians still fear to be seen as "national nannies", if they use nudges (John, 2018). One possible solution for this "trap" might be to invite the people to participate in creating and implementing nudges (John, 2018). Therefore, a "test-learn-adapt-share"-approach is a promising way to create nudges transparently and implement them successfully.

Having these findings in mind one can argue that nudging seems to be a possible pathway to implement more pro-environmental behavior. If the nations reflect on their relation towards the citizens, adapt the style of nudging to their needs, and develops nudges together with the citizens, it can have a positive effect on the behavior. Taking South Korea as an example - people are highly motivated to follow nudges and the country is able to implement them without pressure, protest or misunderstandings. In my point of view it is fundamental to examine the psychological specifics of each nation (as Sunstein et al., 2018, started to do) to understand the view of the people and their prejudices and resentments towards the use of nudging. As the articles show, it is a differentiated picture and no "one-size-fits-all"-programs for a country will lead to a formative change. One needs to understand which nudges fit for which region. Further on one needs to understand the social dynamics in the countryside (how can the citizens be attracted to participate in creating convincing nudges for their area). The same is true for higher educated citizens - they are more critical towards nudges as the articles pointed out. Therefore, it could be useful to find ways to integrate higher educated citizens to take part in the development of nudges. These are all necessary and meaningful steps, but I think one aspect is crucial: Many politicians have the fear to be seen as "national nannies" (John, 2018). The politicians need to understand that it is worthy to start a "test-learn-adapt-share" approach together with the citizens. One could start with regulatory nudges (e. g. default rules), which 
do not provoke psychological reactance (Bang et al. 2018). In my opinion, it is a question of attitude and sure instinct to foster the creation and communicate the implementation of pro-environmental nudges. The effects on the environment are remarkable if the citizens internalize the value of the nudges.

Soman (2013) gives an overview on concrete nudging-projects, which illustrate the on-going development on that field: In the UK, the Government has centralized their efforts with a Behavioural Insights Team, also called "Nudge Unit" which is a standalone government unit that collaborates with business, NGOs, and other government departments to develop and test nudge behaviour. They were established in 2010 and the team has conducted numerous experiments in several areas such as energy usage, debt and fraud or charitable giving. By time, the team has helped to educate and disseminate knowledge throughout the UK government on behavioural economics and its application in public policy. Much success was achieved in identifying various behavioural interventions that resulted in savings of over 300 million Pounds. More than that, the team has achieved a 10-fold return on the costs. By now the government is planning to privatize this Nudge Unit, which will add commercial capacity and investment to the team, so to increase the potential to generate revenue for the government and the taxpayers. Various other departments including the Department for Environment, Food and Rural Affairs, Departement of Energy and Climate Change and last but not least the Department of Health have initiated similar programs on behavioural economics to the Government's knowledge. To ensure that the UK government stays up to date on the latest policy tools, new development in policymaking was mandated, including behavioural science

Concerning the United States, a well-known professor giving lectures at the Harvard Law School, Cass Sunstein, was appointed the administrator of the Office of Information and Regulatory Affairs (OIRA) between 2009 and 2012. He is also co-author of the book "Nudge: Improving Decisions About Health, Wealth, and Hapiness." While being appointed, Sunstein was responsible for many nudge initiatives including the Smart Disclosure Initiative or the redesign of the USDA Food Pyramid as well as the Fuel Economy label. In direct comparison to the success of the UK Behavioural Insights Team, the US has formed the so called "Social and Behavioural Science Team" who will be working with various government agencies together to test and implement behavioural interventions. Right now the team is working on childhood education among low-income families, health compliance and domestic violence. There work is not restricted to these initiates though, as it is their main goal to improve government efficiency and performance mainly through innovation and evidence. It is furthermore in the interest of the state that governmental agencies are being advised to consider applying behavioural insights, again to help improve policy outcomes and lower the operational costs. Other efforts to incorporate behavioural economics are dispersed across various government departments. The USDA for example established the Cornell Center for Behavioral Economics in Child Nutrition. Another example is the Federal Trade Commission, which uses behavioural economics in its policy analysis and participates in various workshops and conferences in this subject. Even the Department of Energy is looking forward to establish its own behavioural science team.

Then there is Denmark, which at the moment does not have a centralized governmental unit for behavioural economics but instead has several departments that are part of the Danish Nudging Network. It is comprised of researchers, practitioners and policymakers who interested in behavioural economics into welfare and policies.

But what about the EU? The European Union has used behavioural economics to design some of their consumer policies. 
New Zealand incorporated behavioural economics into a voluntary savings plan, called Kiwi Saver and their Ministry of Economic Development has also published a report discussing the importance of behavioural economics in policymaking.

\section{Influencers and Nudging}

One other group is relevant in this context: The group of influencers gained more and more power during the last decade. They spread their opinions and views on different channels (Twitter, Instagram, Facebook etc.) and reach millions of people each day. Their business-concept is based on product-placement but it could be enriched by more nudging-associated topics in the future. Follower of the influencers might have a sympathetic ear for nudges presented by them. This part of the so called "digital nudging". Kaiser (2018) could give a short inside into this new aspect of nudging. By definition of Weinemann in 2016 digital nudging means "use of user-interface design elements to guide people's behavior in digital choice environments". In return to conventional nudging, in the center of digital nudging are user interfaces. The authors propose various applications of nudging principles and use cases (Weinemann et al. 2016). Following the definition above, digital nudging consists of two models. Meske and Potthof (2017) suggest one model which is called "digital nudging process model", short DINU. This model sketches a cycle for the design of digital nudges. The second model of Schneider et al. outlines the same content (Schneider et al., 2018). Even though digital nudging is a rather new concept there are several different types of studies about this topic. For example, as policy papers by Gregor and Lee-Archer in 2016, as systematic literature reviews (Mirsch et al., 2017), as research-in-progress papers (Hummel et al., 2017; Lehrer and Jung, 2017; Pahuja and Tan, 2017; Stryja et al., 2017; Székely et al., 2016; Tietz et al., 2016; Weinmann et al., 2017), or also full experimental studies by Schneider et al. (2017). An example for digital nudging shows the use of warnings to avoid the purchase of incompatible digital products online (Esposito et al., 2017)

I think that sustainable production needs to go hand in hand with applied psychology by politicians, which stirs up the citizens and invites them to follow pro-environmental behavior. We can see the effects of advertising psychology - a branch of psychology that is accepted and taught at universities around the world. A big step would be to implement university-courses that strengthen the awareness of the students for the influential capacity of nudges. In addition, NGOs can make more use of nudging that reaches the citizens and influences their mind-set in a positive way.

Convincing nudges can undermine and support all of the 17 millennial goals, because cautious, sustainable "behavior" is the core of each goal. Nudging is playing a crucial role especially concerning topics like peace, justice and strong institutions. This becomes clear, when one takes a look at the Young economic Summit that took place in 2017- their claim was as following: "Industrialized nations' lifestyle is not sustainable as resources are depleted, the environment is degraded and global warming is fueled. This puts the welfare of current and future generations at risk. Fostering sustainable consumption is a major task for reaching the UN's Sustainable Development Goals (SDG). Lifestyles can become more sustainable when for example waste is reduced, fewer fossil fuels are used, or less meat is eaten. Classic economic instruments like taxing waste, resource use or pollution are often not implemented as they are politically unpopular. Subsidies are costly and often not an efficient strategy for influencing behavior. Even if people would like to consume more sustainably they find it hard to break old habits and do things differently compared to what they did before or to what everyone around them does. The challenge is to change consumption habits that are deeply rooted in our minds and in our society. Recently, economics has started to pay attention to findings from psychology about how people's behavior can be changed by nudges. Nudges include changing the order of presentation or the default option when choosing goods, structuring complex 
information clearly, reducing the cognitive burden of actions, or giving people feedback about their behavior. Nudges that work are for example

- Setting a default for offsetting a flight's greenhouse gas emissions when booking a flight. People have to actively deselect buying the offsets.

- Informing a household about its energy consumption compared to its neighbors' consumption.

- At the cash machine, returning the credit card before the money so the card is not forgotten." (https://www.young-economic-summit.org/nudging-sustainable-consumption-2017/)

One can see it in a line with parts of "Positive Psychology" (Maslow, 1954; Seligman, 2012, Tomoff, 2017). The mindset gets the chance to switch the direction to trust, solidarity, and peaceful coexistence. This goes hand in hand with the ideas of the influential psychoanalyst Erich Fromm who pointed out that the modern societies are focused on the mind set of "having" and not on "being" (Fromm, 1976). The "having"-mode is also characterized in the following way: "The nature of the having mode of existence follows from the nature of private property. In this mode of existence all that matters is my acquisition of property and my unlimited right to keep what I have acquired. The having mode excludes others; it does not require any further effort on my part to keep my property or to make productive use of it. The Buddha has described this mode of behavior as craving, the Jewish and Christian religions as coveting; it transforms everybody and everything into some-thing dead and subject to another's power." (Fromm, 1976). So in the state of "having" "my relationship to the world is one of possessing and owning, one in which I want to make everybody and everything, including myself, my property" (Fromm, 1976). The state of "being" "means aliveness and authentic relatedness to the world" (Fromm, 1976). The state of being is characterized as: "The mode of being has as its prerequisites independence, freedom, and the presence of critical reason. Its fundamental characteristic is that of being active, not in the sense of outward activity, of busyness, but of inner activity, the productive use of our human powers. To be active means to give expression to one's faculties, talents, to the wealth of human gifts with which - though in varying degrees - every human being is endowed. It means to renew oneself, to grow, to flow out, to love, to transcend the prison of one's isolated ego, to be interested, to "list," to give." (Fromm, 1976). This state of "being" could be a central theme for nudges, which have a meaningful impact on the behavior of the people.

\section{References}

Byerly, H., Balmford, A., Ferraro, P. J., Wagner, C. H., Palchak, E., Polasky, S., Ricketts, T. H., Schwartz, A. J., \& Fisher, B. (2018). Nudging pro-environmental behavior: evidence and opportunities. Frontier of Ecological Environment, 16, 159-168, doi: $10.1002 /$ fee. 1777

Gigerenzer, G. (2015) On the Supposed Evidence for Libertarian Paternalism DOI: 10.1007/s13164-015-0248-1

Cuthbert, M. O., Gleeson, T., Moosdorf, N., Befus, K. M., Schneider, A., Hartmann J. \& Lehner, B. (2019). Global patterns and dynamics of climate-groundwater interactions. Nature Climate Change, 9, 137-141.

Darby, S. J. (2012). Metering: EU policy and implications for fuel poor households. Energy Policy, 49, 98-106.

Delmas, M. A., Fischlein, M., \& Asensio, O. I. (2013). Information strategies and energy conservation behavior: a metaanalysis of experimental studies from 1975 to 2012. Energy Policy, 61, 729-739.

Egebark, J.,\& Ekström, M. (2013). Can Indifference Make the World Greener? http://www.ifn.se/wfiles/wp/wp975.pdf

Esposito, G., Hernández, P., van Bravel, R., \& Vila, J. (2017). Nudging to prevent the purchase of incompatible digital products online: An experimental study. PLOS ONE, pp. 1-15 (doi: 10.1371/journal.pone.0173333).

Fischer, C. (2008). Feedback on household electricity consumption: a tool for saving energy? Energy Efficiency, 1, 79-104.

Fromm, E. (1976). To Have Or to Be?, New York (Harper and Row)

Goldstein, N. J., Cialdini, R.B., \& Griskevicius V. (2008). A room with a viewpoint: using social norms to motivate environmental conservation in hotels. Journal of Consumers Research, 35 (3) (2008), pp. 472-482.

Gregor, S., \& Lee-Archer, B. (2016). The digital nudge in social security administration. International Social Security Review, pp. 63-83 (doi: 10.1111/issr.12111). 
Hansen, P. G. (2014). Nudge and Libertarian Paternalism: Does the Hand Fit the Glove? Roskilde University, Copenhagen.

Hummel, D., Schacht, S., \& Maedche, A. (2017). Designing Adaptive Nudges for Multi-Channel Choices of Digital Services: A Laboratory Experiment Design. Proceedings of the 25thEuropean Conference on Information Systems (ECIS), pp. 1-12.

John, P. (2018). How far to Nudge: Accessing Behavioural Public Policy. Cheltenham: Edward Elgar.

Kaiser, D. (2018). Individualized choices and digital nudging: Multiple studies in digital retail channels.

Lehner, M., Mont O., Heiskanen, E. (2016). Nudging - A promising tool for sustainable consumption behaviour? Journal of Cleaner Production, 134, p. 166-177.

Lehrer, C., \& Jung, R. (2017). "Save money, book now! - Nudging users to complete online travel bookings". Proceedings of the 23rd Americas Conference on Information Systems (AMCIS), Boston, Massachusetts, USA (available at http://aisel.aisnet.org/amcis2017/HumanCI/Presentations/5).

Maslow, A. H. (1954). Motivation and personality. Brandeis University, New York.

Meske, C., \& Potthoff, T. (2017). The DINU-model - A process model for the design of nudges. Proceedings of the 25th European Conference on Information Systems (ECIS), pp. 2587-2597.

Mirsch, T., Lehrer, C., \& Jung, R. (2017). Digital Nudging : Altering User Behavior in Digital Environments. 13th International Conference on Wirtschaftsinformatik, pp. 634-648.

OECD. (2017). Behavioral Insights and Public Policy: Lessons From Around the World. Paris: OECD Publishing.

Pahuja, A., \& Tan, C.-H. (2017). Breaking the Stereotypes: Digital Nudge to Attenuate Racial Stereotyping in the Sharing Economy. Proceedings of the 38th International Conference on Information Systems (ICIS), pp. 1-8.

Ruggery, K. (Ed.) (2018) Behavioral Insights for Public Policy: Concepts and cases. London: Routledge.

Schneider, C., Weinmann, M., \& Vom Brocke, J. (2018). Digital Nudging-Influencing Choices by Using Interface Design. Communications of the ACM (January), pp. 1-11.

Schneider, D., Lins, S., Grupp, T., \& Benlian, A. (2017). Nudging Users Into Online Verification: The Case of Car sharing Platforms. Proceedings of the 38th International Conference on Information Systems (ICIS), pp. 1-20.

Seligman, M. E. P. (2012). Flourish - Wie Menschen aufblühen. Kösel-Verlag, München, ISBN 978-3-466-30934-4.

Soman, D. (2013). Nudging around the world. https://www.um.es/documents/1922922/1973600/Nudging+Around+The+World.pdf/3af04386-ba8b-4742-b33973626 bf 2 be 94

Sunstein, C. R., Reisch, L. A., \& Kaiser, M. (2018). Trusting nudges? Lessons from an international survey. Journal of European Publuc Policy. https://doi.org/10.1080/13501763.2018.1531912

Stryja, C., Dorner, V., \& Riefle, L. 2017. Overcoming Innovation Resistance beyond Status Quo Bias - A Decision Support System Approach. Proceedings of the 50th Hawaii International Conference on System Sciences (HICSS), pp. 567576.

Székely, N., Weinmann, M., \& Vom Brocke, J. (2016). Nudging People To Pay Co2 Offsets - The Effect of Anchors in Flight Booking Processes. Proceedings of the 24th European Conference on Information Systems (ECIS), Istanbul, Turkey, pp. 1-10.

Thaler, R. H., \& Sunstein, C. R. (2008). Nudge - Improving decisions about health, wealth and happiness. Yale University Press, New Haven \& London.

Thaler, R. H., Sunstein, C. R. \& Balz, J. P. (2010). Choice architecture. http://dx.doi.org/10.2139/ssrn.1583509.

Tietz, M., Simons, A., Weinmann, M., \& Vom Brocke, J. (2016). The Decoy Effect in Reward-Based Crowd funding: Preliminary Results from an Online Experiment. Proceedings of the 37th International Conference on Information Systems (ICIS), pp. 1-11.

Tomoff, M. (2017). Kritisch hinterfragt - Positive Psychologie - Erfolgsgarant oder Schönmalerei? Springer, Wiesbaden. ISBN 978-3-662-50386-7.

Weinmann, M., Schneider, C., \& vom Brocke, J. (2016). "Digital Nudging," Business \& Information Systems Engineering, Springer Fachmedien Wiesbaden (doi: 10.2139/ssrn.2708250).

Weinmann, M., Simons, A., Tietz, M., \& vom Brocke, J. (2017). Get It before It's Gone? How Limited Rewards Influence Backers' Choices in Reward-Based Crowdfunding. Proceedings of the 38th International Conference on Information Systems (ICIS), pp. 1-10.

Whitehead, M., Jones, R. lilley, R., Pykett, J. \& Howell, R. (2017). Neuroliberalism: Behavioural Government in the Twenty-First Century. New York: Routledge. 